\section{NATIONAL CHEMICAL LABORATORY OF INDIA}

\author{
By DR. BASHIR AHMAD
}

Assistant Director of Planning, National Chemical Laboratory

$I^{\mathrm{N}}$ pursuance of the recognition of the need for the organisation of scientific and technical research on an extensive scale for the larger objective of economic and industrial development of the country, it has been proposed to establish a National Chemical Laboratory in India. A tentative scheme for the Laboratory was drawn up in 1943 and circulated to a large number of scientific organisations and individuals in India and abroad. A final plan has now been formulated after a careful consideration of the suggestions received, the lines along which similar laboratories in other countries have been established, and taking into consideration also the special needs of India. This plan, therefore, incorporates the views and recommendations of a large number of leading men of science and scientific organisations all over the world.

\section{Functions}

The Laboratory will be devoted to problems of both fundamental and applied research in different fields of chemistry, and will also concern itself with developing the means for the application of scientific knowledge to practical problems of industry. The Laboratory will bridge the gulf between science and its application to industry and will provide a link between the universities, the State and other scientific institutes on one hand, and industry on the other. The fundamental work undertaken by the Laboratory will be devoted to extending the frontiers of knowledge in directions likely to prove useful to the industrial progress of the country. The applied and developmental work will take the form of improving old processes in the light of newer scientific knowledge, and discovering new processes. This work will be carried to the pilot-plant scale in the Laboratory, after which it will be passed on to industry. The Laboratory will maintain close and continual contact with industry, the difficulties and problems of which may be referred to the Laboratory for solution. In this manner the link between the National Chemical Laboratory and industry will be vital and effective, and so will be its link with the universities and other scientific institutes in the country.

Some of the most important scientific discoveries during the last half a century, which have been of the greatest benefit to mankind, have resulted from large organisations both of workers and of materials, and have involved expenditure beyond the means of an average research laboratory. The National Chemical Laboratory hopes to be in a position to undertake such important and expensive research.

Keeping in view the fact that problems of industry, or in the wider perspective, those of human welfare, require the co-operation of experts in different fields of science, the scope of the National Chemical Laboratory has been kept sufficiently wide. The Laboratory will include not only chemistry, but also physics, mineralogy, engineering and biology in so far as they relate to chemical problems and the chemical utilization of the national resources. The Laboratory will also provide a place for the training of research workers in specialized fields of chemistry and technology, particularly with reference to those for which there is no provision available in the existing scientific laboratories of India.

The scientific work of the National Chemical Laboratory will be divided into seven main divisions : (1) Inorganic Chemistry, including Analytical Chemistry; (2) Physical Chemistry, including Electrochemistry; (3) Chemistry of High Polymers; (4) Organic Chemistry; (5) Biochemistry, including Biological Evaluation; (6) Chemical Engineering; (7) Survey and Intelligence. In addition to these, two more Divisions are contemplated, one for Fermentation Technology, and another for Cellulose and Related Products.

\section{Location and Staff}

Poona, which enjoys a moderate climate all the year round, and is within easy reach of Bombay and its industries, has been selected for the location of the Laboratory. A site of about 470 acres on the Pashan Road on a beautiful, breezy and healthy plateau, in close proximity to educational institutions of the city, has been selected for the Laboratory.

The staff requirements of the Laboratory have been carefully considered. They are summarized below :

1. Scientific staff :

(a) Director, Assistant Directors, Senior Scientific Officers, Junior Scientific

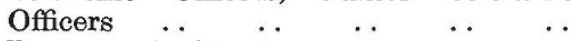

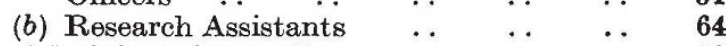

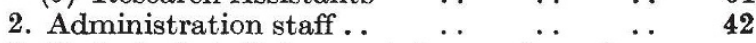

3. Technical staff for workshop and various services $\ldots$. . . . . . .

4. Stores, Laboratory Assistants and Attend$\begin{array}{lllllll}\text { ants } \ldots & \ldots & \ldots & \ldots & \ldots & \ldots & 86\end{array}$

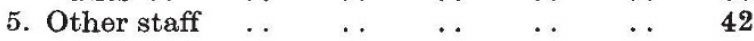

$$
\text { Total } \quad \ldots \quad \overline{320}
$$

\section{Buildings and Finances}

The floor-space requirements of buildings to house the different activities of the Laboratory have also been carefully worked out. These are as follows :

1. Main building, housing various

divisions .. .. . .

. 30,000 ,

$$
\text { Total .. } \overline{180,000} \text {, }
$$

The establishment of the Laboratory will involve a capital expenditure of 3.5 million rupees and an annual budget of 1.16 million rupees when the Laboratory is working at full strength.

\section{NATIONAL METALLURGICAL LABORATORY OF INDIA}

\author{
By Dr. G. P. CONTRACTOR
}

\section{Assistant Director of Planning, National Metallurgical} Laboratory

THAT India possesses great natural advantages for the production of iron and steel there is no doubt. She has rich and vast deposits of iron ore, exceeding both in quality and quantity the ores found in many States of Europe and America. These ores are reckoned to be more than sufficient for the requirements of India herself for nearly a thousand years. In spite of this, India's yearly pro. 